\title{
The Mediating Role of Learning Strategy in the Relationship between Achievement Goals and
} Academic Achievement

\author{
Caroline Atieno Obura (Corresponding Author) \\ School of Education, Department of Educational Psychology \\ Kenyatta University \\ P.O. Box 43844-00100 \\ Nairobi, Kenya \\ Tel: 254-720-221-749Ｅ-mail: carolyneobura@yahoo.com
}

Received: August 19, 2019 Accepted: September 18, 2019 Published: September 30, 2019

doi:10.5296/ijld.v9i3.15295 URL: https://doi.org/10.5296/ijld.v9i3.15295

\begin{abstract}
The study examined the mediating role of learning strategies in the relationship between achievement goals and academic achievement. The study sample consisted of 597 students selected from 13 schools using purposive, stratified, proportionate and simple random sampling procedures. The study adopted a correlational research design to establish mediation of learning strategy in the relationships between achievement goals on academic achievement. Students' achievement goals and learning strategy scales were adapted to measure achievement goals and learning strategies. Results of the study showed that there was a partial mediation of deep learning in the relationship between mastery goals and academic achievement. Partial mediation of surface learning strategy was equally reported, in the relationship between performance-approach goals and academic achievement.
\end{abstract}

Keywords: achievement goals, performance-avoidance goals, performance-approach goals, mastery goals, deep learning strategy, surface learning strategy

\section{Introduction/ Background of the Study}

Globally academic achievement plays a significant role in every sphere of life. At the individual level, it can be used to determine whether a student can be promoted to the next educational level such as secondary school or university. Academic achievement has societal importance as well. Information about a nation's academic achievement can be used to 
examine the educational system of a nation and inform on educational policy decisions. Due to great importance attached to academic achievement, governments of different countries and many families devote a lot of resources and time in preparation of students for success (Bücker, Nuraydin, Simonsmeier, Schneider, \& Luhmann, 2018). Due to the importance placed on the domain, poor academic achievement is therefore a serious problem.

As students progress to secondary school, they begin to experience greater competition and performance evaluation. They get exposed to various learning experiences. They learn new skills, are examined, graded and ranked according to their academic performance in comparison to other students. In the process, they set certain academic goals which may either focus their attention to the adoption of goals to excel in examinations, to perform better than others or to understand a concept. Academic goals guide students' behaviour in a school setting by helping students to structure their time so that they can focus on what is important to them. Academic performance, which is measured by examination results, therefore becomes one of the major goals of students as well as teachers in schools (Elliot, 1999). According to Anderman and Patrick (2012), the achievement goals that are adopted by students in school may have an influence on their academic achievement.

Two qualitatively different achievement goal constructs emerge when individual students are involved in academic goal-setting activities. These constructs are "mastery" and "performance" goals. Students who are performance goal-oriented tend to focus on outperforming others, on demonstrating behaviour that would lead to public recognition or praise and prefer easy tasks (Anderman and Patrick, 2012; Phan, 2013).

Students, who adopt performance-approach goals, will tend to emphasis on outperforming others and demonstrating behaviour that would lead to public recognition or praise. They will do whatever it takes to outperform others in a class (Grant \& Dweck, 2003). Adoption of performance goals may subject them to feelings of humiliation, especially, when they are ranked below their peers in academic achievement. Students' adoption of performance-approach goals may lead to surface-level strategies like rote learning or cramming concepts for examination to get higher grades. A few of these students may end up scoring high academic grades without content mastery. Others may even cheat in examinations to protect their self-worth and demonstrate to teachers, parents, and classmates that they are smarter than others. Others may end up performing poorly and therefore fail to reach their full potential and to become useful members of the society. There are those who may embrace performance-avoidance goals which are grounded in the desire to avoid appearing incompetent to others. Such students are likely to experience evaluative anxiety, and this may influence them to use surface strategies that help them not to appear less competent, for example, by withdrawing effort (Elliot, 1999; Hornstra, Majoor \& Peetsma, 2017; Peetsma \& Van der Veen, 2013). Usually, such surface learning strategies are less effective in achievement contexts. As a result, their performance goals may undermine their academic performance.

On the other hand, mastery-oriented students tend to develop competence by prioritising on learning, improvement and comprehension. Such students adopt strategies that help them improve their academic achievement (Grant \& Dweck, 2003). The link between achievement 
goals, learning strategy and academic achievement remains unexplored. This study examined this link.

\subsection{Objectives of the Study}

The study was to determine the mediating role of learning strategies in the relationship between, achievement goals and students' academic achievement.

\subsection{Research Hypothesis}

$\mathrm{H}_{\mathrm{a} 1}$ : Learning strategies significantly mediate the relationship between achievement goals and academic achievement.

\subsection{Significance of the Study}

The findings may help teachers explain why some students adopt surface level strategies like rote learning.

\section{Review of Related Literature}

\subsection{The Mediation of Learning Strategies in the relationship between Achievement Goals and} Academic Achievement

In Croatia, Miškulin and Vrdoljak (2017) examined the relationship between goal orientation, learning approaches and academic achievement among 346 undergraduate students, conveniently sampled. The students were aged between 19 and $31(\mathrm{M}=21.84, \mathrm{SD}=1.686)$. The researchers also examined the possibility of predicting achievement through goal orientation and learning approaches. The study applied hierarchical regression analysis to predict academic success based on goal orientation and study approaches. The results showed that academic achievement was positively correlated with mastery goals, performance goal and deep learning but negatively correlated with avoidance goals and surface learning. There were positive correlations among mastery goals and deep learning, avoidance goals and surface learning. A negative correlation between avoidance goals and deep learning were also observed. The study did not use a representative sample, and therefore their finding cannot be generalised. It was, therefore, necessary to conduct a similar study using a representative sample. The study was conducted among older students whose ages ranged between 19 and 31 unlike in the current study where the participants were younger $(\mathrm{M}=18.52 \mathrm{SD}=0.89$.

Nasiri, Pour-Safar, Taheri, Sedighi-Pashaky, \& Asadi-Louyeh (2017) conducted a study among 175 medical students in Guilan University enrolled in a second-year class to show a causal model of academic achievement based on goal orientation and learning strategies. The data were analysed using Pearson Product Moment Correlation coefficient and structural equation modelling. The mediator analysis of Baron and Kenny (1986) was used to measure the mediating role of learning strategies in the relationship between goal orientation and academic achievement.

Results from the Pearson correlation test showed a significant association between learning orientation and deep learning strategy. A significant negative correlation between learning orientation, performance orientation and surface learning strategies was reported. The 
relationship between avoidance goal orientation and surface learning strategy was equally significant and positive. A significant positive correlation was also reported between deep learning strategy and academic achievement. A negative correlation between surface learning strategy and academic achievement was also indicated. Structural model standard regression coefficient showed a significant positive correlation between learning goals, performance goals and deep learning. The findings also showed significant negative correlations between avoidance goal orientation and deep learning strategy. The mediating effect was confirmed. The total effect was significant. Given that the sample was drawn from university students, it was difficult to generalise the findings to high school students. There was need, therefore, to conduct the current study in Kenya, using a sample drawn from secondary school students in a different school setting.

Kadioglu (2014)carried a study to examine the relationship between learning strategies and goal orientations of Turkish high school students in Chemistry subject. The learning strategies were grouped into four, namely, critical thinking, metacognitive, self- regulation, rehearsal and elaboration. The sample consisted of 1157 students. The study used a correlational design. The Cognitive and Metacognitive Strategies Scale was used to measure the learning strategies. The $2 \times 2$ Goal Orientation Scale was used to measure goal orientations of the students. The study used a multilevel regression model to analyse each strategy type. Achievement goals of students were tested as predictors of cognitive and metacognitive strategies. The study reported that performance-approach and mastery-approach were positive predictors of the students learning strategies. Mastery goals had a higher beta coefficient; the variation in elaboration strategies was explained more by mastery-approach than performance-approach goals. The study found a significant relationship between mastery-approach and deep learning strategies.

Contrary to previous findings that have been reported in the related literature, the study also reported that performance-approach goals were linked to strategy use. Avoidance-oriented goals were not significant predictors of learning strategies. Avoidance-approach goals were reported to be less frequently used by the students in the study. Whereas the study examined the relationship between achievement goals and learning strategies of Turkish high school students in Chemistry, the current study examined high school students' performance in all the eight subjects. The current study has also extended the previous study by examining the mediating role of learning strategies in the relationship between achievement goals and academic achievement which was not part of the previous study.

Senko, Hama and Belmonte (2013) conducted two studies to explore the relationship between mastery-approach, performance-approach goals and students' adoption of learning strategies at an American public university. The study used a sample of 163 students $(\mathrm{N}=6500) .85 \%$ of the respondents were females of an average age of 23.4. The first study examined the predictive relationship between mastery-approach goals and deep learning strategy. The first study also tested the relationship between performance-approach goals and surface learning strategy. Finally it investigated whether avoidance goals discouraged deep and surface learning strategies. The second study assessed participants' exam preparation strategies. The items that were measured included surface learning and deep learning. The results indicated that 
mastery-approach goals predicted the use of the deep learning strategy $(\beta=.26)$, while, performance-approach goals predicted the use of the surface learning strategy $(\beta=.15)$. Avoidance goals predicted low use of deep learning $(\beta=-.18)$ and surface learning $(\beta=-.25)$.

The second part of the study tested the impact of goals and learning strategies on students' exam performance. The study expected performance-approach goals to predict high grades but did not expect the same from mastery goals. The study also tested whether learning strategies influenced academic achievement. The study reported that performance-approach goals predicted high usage of a surface learning strategy $(\beta=.26)$. Mastery goals predicted high usage of a deep learning strategy $(\beta=.20)$. Performance-approach goals surprisingly also predicted high usage of a deep learning strategy $(\beta=.16)$. Examination of the links between achievement goals, learning strategies and exam performance showed that students who adopted performance-approach goals scored high grades on the exam $(\beta=.18)$. Those who pursued mastery-approach goals, also surprisingly scored high grades $(\beta=.21)$. Deep learning strategies were unrelated to achievement, while surface learning strategies predicted low exam performance $(\beta=-.19)$. Surface learning strategies did not provide the expected negative indirect effect on performance approach goals, then to achievement. Although the sample matched university campus norms for all demographics, it included disproportionately more females. The data collection method adopted by the study made it impossible to control for gender differences.

\subsection{Summary of Review of Related Literature}

From the review of related literature, there was evidence that substantial studies on achievement goals and learning strategies and academic achievement have been done. However, these studies had been carried out in western countries where the learning experiences could be very different from that of Kenya. Secondly, many of those studies used samples from college undergraduate students and elementary schools and therefore the results may not be generalised to the high school population.

\section{Research Design and Methodology}

\subsection{Research Variables}

The predictor variable in the study was achievement goals. It had three levels: mastery, performance-approach, and performance-avoidance. It was measured at an interval level of measurement using scores on adapted scales. Learning strategy was the mediator variable. It had two levels: deep and surface learning. Academic achievement was the outcome variable. It was measured at an interval level. It was defined as the mean score in all subjects in three subsequent end term examinations. The mean scores were then converted into t-scores to enable them to be comparable to the sample.

\subsection{Research Instruments}

Students' questionnaire and pro forma summary of students' examination results were used for data collection. Students' demographic records were taken from school records. 


\section{I Macrothink}

\subsubsection{Achievement Goal Questionnaire}

The instruments to measure mastery goals, performance approach, and performanceavoidance were adapted from Patterns of Adaptive Learning Survey (PALS) (Midgley et al., 2000). The use of PALS is controlled by conditions set by the developer of the instrument that is, that user properly acknowledges and attributes it to the University of Michigan. The instrument was further sub-divided into three sections. Section I measured mastery goals using mastery goals subscale. It had eight items. The expected minimum score was eight while the maximum was 40. Section II measured performance-approach goals using performance-approach goals subscale. It had seven items. The expected minimum score was seven, while the maximum was 35. Section III consisted of seven items which sought information on respondents' orientation towards performance-avoidance goals using performance-avoidance goals subscale. The expected minimum score was seven and the maximum was 35 .

\section{Students' Learning Strategies Questionnaire}

The questionnaire was subdivided into two sections. Section I had five items which measured deep learning strategies. The expected minimum was 5, and the maximum score was 25 . Section II had surface learning strategy scale which had six items. The expected minimum was 6 , while, the maximum score was 30 .

\subsection{Location of the Study}

The study was conducted in Nairobi City County. Nairobi City County is one of the 47 Counties in the Republic of Kenya.

\subsection{Population of the Study}

Form three students in Nairobi County schools formed the target population. The accessible population consisted of 6027 Form three students in 38 public secondary schools in Westlands, Starehe, Langata and Dagoretti Sub Counties of Nairobi. The study used a sample 597 participants, 314 boys and 283 girls.

\subsection{Data Analysis}

The data from the questionnaires were were coded, awarded numerical scores and entered into the computer for statistical analysis using version 24 Statistical Package for Social Sciences (SPSS).

\subsubsection{Hypothesis Testing}

Pearson Product Moment Correlation Coefficient analysis was used to measure the relationship between the predictor variable, achievement goals and outcome variable, academic achievement. Stepwise multiple regression analysis was also done to determine the significant predictors of academic achievement. The level of significance in this study was set at $p=.05$, which is the level deemed acceptable for social science research (McMillan, 2012). The following specific null hypotheses were tested at $p=.05$ using the indicated statistical tests: 
$\mathrm{H}_{01}$ : There is no significant relationship between achievement goals and academic achievement.

To make the hypothesis more testable, the following supplementary null hypotheses were formulated:

$\mathrm{H}_{01.1:} \quad$ There is no significant relationship between mastery goals and academic achievement.

$\mathrm{H}_{012.2:}$ There is no significant relationship between performance-approach goals and academic achievement.

$\mathrm{H}_{01.3 \text { : }} \quad$ There is no significant relationship between performance-avoidance goals and academic achievement.

To test the second null hypothesis, multiple regression analysis was used to determine whether learning strategies mediated the relationship between the two levels of school psychological environment and academic achievement.

$\mathrm{H}_{02}$ : Learning strategies do not significantly mediate the relationship between achievement goals and academic achievement.

The following supplementary null hypotheses were further advanced to make the null hypothesis testable:

$\mathrm{H}_{02.1}$ : Deep learning strategies do not significantly mediate the relationship between mastery goals and academic achievement.

$\mathrm{H}_{02.2 \text { : }} \quad$ Surface learning strategies do not significantly mediate the relationship between mastery goals and academic achievement.

$\mathrm{H}_{02.3 \text { : }} \quad$ Deep learning strategies do not significantly mediate the relationship between performance- approach goals and academic achievement.

$\mathrm{H}_{02.4 \text { : }} \quad$ Surface learning strategies do not significantly mediate the relationship between performance- approach goals and academic achievement.

$\mathrm{H}_{02.5 \text { : }} \quad$ Deep learning strategies do not significantly mediate the relationship between performance- avoidance goals and academic achievement.

$\mathrm{H}_{02.6} \quad$ Surface learning strategies do not significantly mediate the relationship between performance-avoidance goals and academic achievement.

To further explore the null hypotheses, the researcher used a mediation model based on a four-step approach as proposed by Baron and Kenny (1986). In the first, step the researcher shows that the independent variable is a significant predictor of the dependent variable (path $\mathrm{c}$ ). In Step two, the initial variable is correlated with the mediator. In other words, the mediator variable is treated as an outcome variable (path a). In step three, the correlation between the mediator variable and the outcome variable is established (path b). In other words, the initial variable is controlled while; the correlation between the two other variables is established. In the last step, the complete mediation across the variables is established. This is only achieved 


\section{Macrothink}

International Journal of Learning and Development

ISSN 2164-4063 2019, Vol. 9, No. 3

when the influence of the initial variable over the outcome variable while controlling for mediator variable is zero. A partial mediation is reported when only the first three steps are satisfied (Baron \& Kenny, 1986). The model is presented in Figure 1.

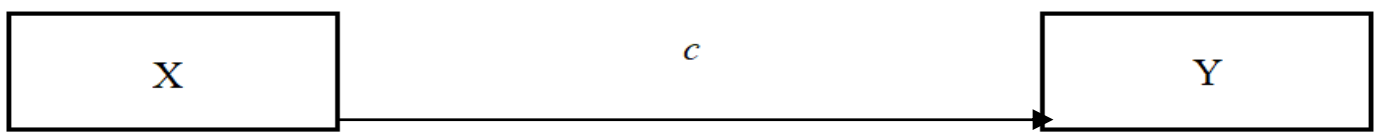

a. Direct pathway

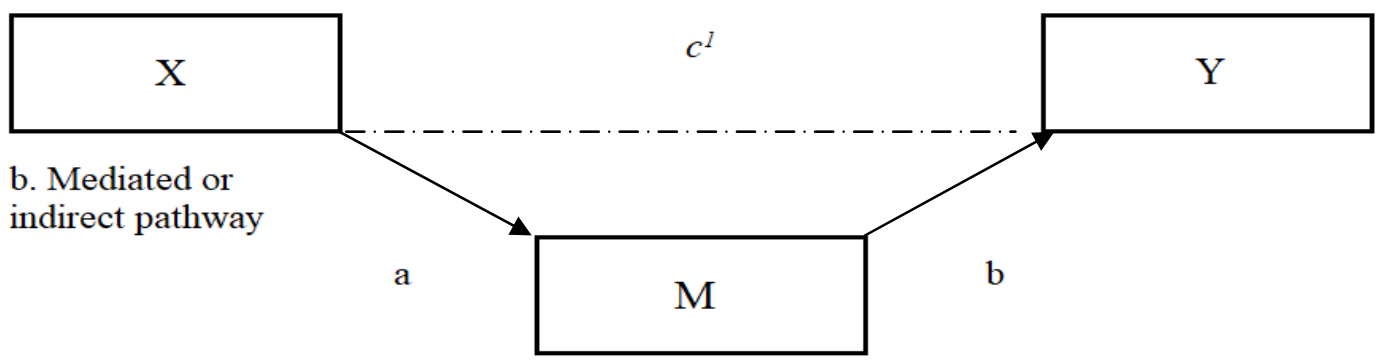

Figure 1.Mediation model (adapted from Hayes, 2013) $\mathrm{X}=$ predictor variable; $\mathrm{Y}=$ outcome variable; $\mathrm{M}=$ mediator variable; $\mathrm{a}=$ parameter relating predictor and mediator variable; $\mathrm{b}=$ parameter relating mediator variable and outcome variable; $c=$ parameter relating predictor and outcome variable; $c^{l}=$ indirect effect.

\section{Findings, Interpretation, and Discussion}

\subsection{Findings and Interpretation}

Before the mediation analysis was done, it was deemed necessary by the researcher to ensure that the data were screened to ensure that they met the assumptions of parametric tests. First Pearson Product Moment Correlation Coefficient was used to examine whether there were relations between the variables. The assessment of multiple correlations between the independent variables was necessary to identify any multicollinearity present and the variables manifesting it most to exclude them from the final model. According to Kock and Lynn (2012) multicollinearity occurs when two or more of the predictor variables have a strong correlation and therefore negatively affects the results of regression analysis. It is recommended that a variable whose correlation results meet or exceed a value of 0.7 should be removed from the regression analysis (Duzan \& Shariff, 2016). The results of the correlations are presented in Table 1. 
Table 1. Correlations of Main Variables

\begin{tabular}{|c|c|c|c|c|c|c|c|c|c|c|}
\hline & & Acad. Ach & MG & & PAP & PAV & $\mathrm{PF}$ & MF & SL & $\mathrm{DL}$ \\
\hline \multirow{3}{*}{ Acad. Ach. } & Pearson Correlation & 1 & & & & & & & & \\
\hline & Sig. (2-tailed) & & & & & & & & & \\
\hline & $\mathrm{N}$ & 597 & & & & & & & & \\
\hline \multirow{3}{*}{ MG } & Pearson Correlation & $.17^{* *}$ & 1 & & & & & & & \\
\hline & Sig. (2-tailed) & .00 & & & & & & & & \\
\hline & $\mathrm{N}$ & 597 & 597 & & & & & & & \\
\hline \multirow{3}{*}{ PAP } & Pearson Correlation & $.18^{* *}$ & .055 & & 1 & & & & & \\
\hline & Sig. (2-tailed) & .00 & .18 & & & & & & & \\
\hline & $\mathrm{N}$ & 597 & 597 & & 597 & & & & & \\
\hline \multirow{3}{*}{ PAV } & Pearson Correlation & $-.15^{* *}$ & & $-.13^{* *}$ & $.155^{* *}$ & 1 & & & & \\
\hline & Sig. (2-tailed) & .000 & .001 & & .000 & & & & & \\
\hline & $\mathrm{N}$ & 597 & 597 & & 597 & 597 & & & & \\
\hline \multirow{3}{*}{ SL } & Pearson Correlation & $.10^{*}$ & .00 & & $.10^{*}$ & -.01 & $.10^{*}$ & .05 & 1 & \\
\hline & Sig. (2-tailed) & .013 & .945 & & .012 & .799 & .012 & .253 & & \\
\hline & $\mathrm{N}$ & 597 & 597 & & 597 & 597 & 597 & 597 & 597 & \\
\hline \multirow{3}{*}{ DL } & Pearson Correlation & $.34^{* *}$ & $.13^{* *}$ & & .08 & -.03 & -.01 & $.11^{* *}$ & $-.09^{*}$ & 1 \\
\hline & Sig. (2-tailed) & .000 & .001 & & .057 & .427 & .860 & .007 & .031 & \\
\hline & $\mathrm{N}$ & 597 & 597 & & 597 & 597 & 597 & 597 & 597 & 597 \\
\hline
\end{tabular}

There was no variable in the current study whose correlation exceeded .07 , and therefore all were included in the regression analysis. The results presented in Table 1 shows that none of the correlations was high enough to indicate multicollinearity. There were statistically significant correlations between mastery goals and deep learning strategy; [ $\mathrm{r}(597)=.13^{* *}$, $p<.05]$. There were no statistically significant correlations between performance-approach goals and deep learning strategies; $[\mathrm{r}=(595), p=.08]$. Surface learning strategy had significant relationships with performance-approach goals, $r(595)=.10^{* *}, p<.05$.

Normality test of residuals was done to screen for violation of normality assumption. In linear regression analysis, it is assumed that the residuals should be normally distributed. In this study, this assumption was tested using a normal Q-Q plot. It is assumed that the residuals are normally distributed, when all the values appear to lie on a straight line, while, cutting across the diagonal (Pallant, 2007). Kolmogorov-Smirnov and Shapiro Wilk tests were also used. Normality was indicated by a $P$-value above 0.05 , significance level. The results are presented in Table 2. 


\section{Macrothink}

International Journal of Learning and Development

ISSN 2164-4063 2019, Vol. 9, No. 3

Table 2. Tests of Normality

\begin{tabular}{lllllll}
\hline & \multicolumn{3}{l}{ Kolmogorov-Smirnov $^{\mathrm{a}}$} & \multicolumn{4}{l}{ Shapiro-Wilk } \\
\cline { 2 - 7 } & Statistic & $\mathrm{df}$ & Sig. & Statistic & $\mathrm{df}$ & Sig. \\
\hline Unstandardized Residual & .033 & 597 & .172 & .997 & 597 & .374
\end{tabular}

Lilliefors Significance Correction.

The results for the test of normality as presented in Table 2 indicate that the residuals were normally distributed as the p-values for both Kolmogorov-Smirnov and Shapiro Wilk tests were greater than $0.05, p=0.172$ and 0.374 respectively.

According to Lewis \& Linzer (2013), in regression analysis, it is assumed that the error terms are the same across all values of the independent variables. The study used a residual scatter plot for predicted scores as well as standardized residual values (errors of prediction) to test for homoscedasticity. Homoscedasticity is the constancy of variance (Salkind, 2010). The assumption is met when the scores are concentrated about 0 point and distributed in a rectangular pattern. The assumption is met when the scores are randomly scattered about a horizontal line as indicated in Figure 2.

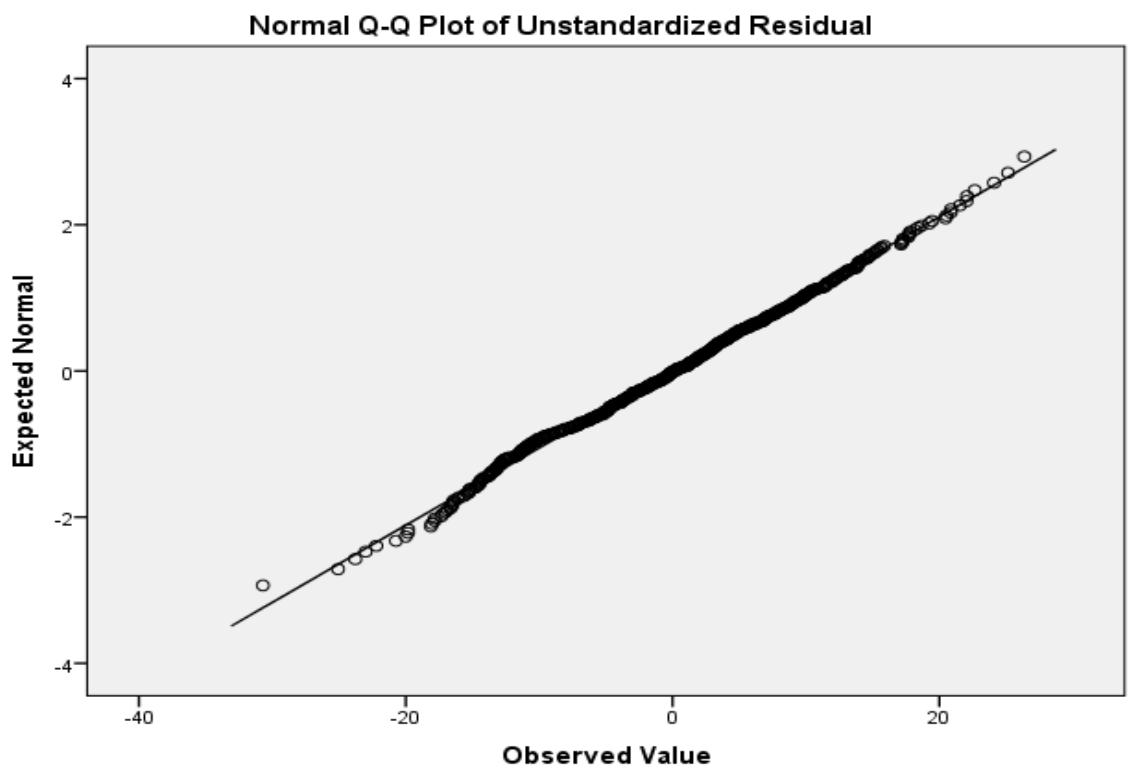

Figure 2. Linearity Plots showing Normal Q-Q Plot of unstandardized residuals for the regression model of academic achievement

In Figure 2 the results showed that the scores were evenly and randomly distributed. They were also concentrated around the horizontal line. This indicated that the homoscedasticity assumption was not violated. Using mediation model based on a four-step approach (Baron and Kenny, 1986) the researcher only tested null hypotheses that had met the conditions for mediation. 
Table 2. Regression Model of Mediation of Deep Learning Strategy in the Relationship between Mastery Goals and Academic Achievement

\begin{tabular}{lllllll}
\hline Model & & \multicolumn{2}{l}{ Unstandardized coefficients } & \multicolumn{2}{l}{$\begin{array}{l}\text { Standardized } \\
\text { coefficients }\end{array}$} & \multicolumn{2}{l}{ 95\% CI } \\
\cline { 3 - 7 } & & B & SE & B & T & Sig \\
\hline 1 & Constant & 39.96 & 2.45 & & 16.34 & 0.00 \\
& MG & 0.31 & 0.08 & 0.17 & 4.16 & 0.00 \\
\hline 2 & Constant & 17.98 & 1.16 & & 15.54 & 0.00 \\
& MG on DL & 0.11 & 0.04 & 0.13 & 3.21 & 0.00 \\
\hline \multirow{3}{*}{3} & Constant & 27.48 & 2.74 & & 10.02 & 0.00 \\
& DL on Ach & 0.69 & 0.08 & 0.33 & 8.47 & 0.00 \\
& MG on Ach. & 0.23 & 0.07 & 0.13 & 3.26 & 0.00 \\
\hline
\end{tabular}

Model 1: $R=.17 ; \mathrm{R}^{2}=.03$, Adjusted $R^{2}=.03, S E=9.85, F(1,595)=17.32, p<.00$

Model 2: $R=.13 ; \mathrm{R}^{2}=.02$, Adjusted $R^{2}=.02, S E=4.66, F(1,595)=10.31, p<.00$

Model 3: $R=.37 ; \mathrm{R}^{2}=.13$, Adjusted $R^{2}=.13, S E=9.31, F(2,594)=45.58, p<.00$

$N=597 ; C I=$ confidence interval, $\mathrm{MG}=$ mastery goals; $\mathrm{DL}=$ deep learning; Ach. $=$ academic achievement.

In Table 2, results obtained from multiple regression analysis are presented. A series of multiple regression analyses were conducted to test whether a deep learning strategy mediated the relationship between mastery goals and academic achievement. In the first step, mastery goals predicted academic achievement $(F(1,595)=17.32, p<.01)$ providing evidence of a significant relationship to be mediated. Mastery goals were found to be significantly related to academic achievement $(\beta=.17)$. There was a statistically significant relationship between mastery goals and deep learning strategies, $(F(1,595)=10.31, p<.01)$. An increase in mastery goals corresponded to an increase in deep learning strategy. The relationship between deep learning strategy and academic achievement was statistically significant $(F(1,595)=.33$, $p<.00$ ) when controlling for mastery goals. An increase in deep learning strategy was associated with an increase in academic performance. The estimate of the mediated influence was found to be equal to the product $a b=(0.11)(0.69)=0.076$. The results showed that mastery goals were related to academic achievement when controlled for deep learning confirming evidence of a partial mediation. Mastery goals were related to academic achievement; $\mathrm{t}=3.26, p<.001$. Coefficient $\mathrm{c}=.13$, which was significant. Mastery goals were related to deep learning strategy; $\mathrm{t}=3.21, p<.001$. Coefficient $\mathrm{a}=.13$, which was equally significant. The deep learning strategy was related to academic achievement when controlled for mastery goals; $\mathrm{t}=8.47, p<.001$. Coefficient $\mathrm{b}=.33$. Mastery goals were related to academic achievement when controlled for deep learning strategy; $\mathrm{t}=3.26, p<.001$. Coefficient $\mathrm{c}^{\prime}=.13$, which was significant. Beta decreased from .17 to .13 , showing partial mediation. The findings led to the conclusion that deep learning strategy partially and 


\section{Macrothink}

significantly mediated the relationship between mastery goals and academic performance. The second mediation model tested the relationship between performance-approach goals, learning strategies and academic achievement. The results are presented in Table 3.

Table 3.Regression Model of Mediation of Surface Learning Strategy in the Relationship between Performance-Approach Goals and Academic Achievement

\begin{tabular}{lllllll}
\hline Model & & \multicolumn{2}{l}{ Unstandardized coefficients } & \multicolumn{2}{l}{$\begin{array}{l}\text { Standardized } \\
\text { coefficients }\end{array}$} & \multicolumn{2}{l}{$95 \%$ CI } \\
\cline { 3 - 7 } & & B & SE & B & T & Sig \\
\hline 1 & Constant & 44.15 & 1.35 & & 32.59 & 0.00 \\
& PAP & 0.26 & 0.06 & 0.18 & 4.52 & 0.00 \\
\hline 2 & Constant & 13.06 & 0.89 & & 14.62 & 0.00 \\
& PAP on SL & 0.09 & 0.04 & 0.10 & 2.52 & 0.00 \\
\hline \multirow{2}{*}{3} & Constant & 42.47 & 1.58 & & 26.96 & 0.01 \\
& SL on Acad & 0.13 & 0.06 & 0.08 & 2.08 & 0.04 \\
& PAP on Acad & 0.25 & 0.06 & 0.17 & 4.9 & 0.00 \\
\hline
\end{tabular}

Model 1: $R=.18 ; \mathrm{R}^{2}=.03$, Adjusted $R^{2}=.03, S E=9.83, F(1,595)=20.46, p<.00$

Model 2: $R=.10 ; \mathrm{R}^{2}=.01$, Adjusted $R^{2}=.01, S E=6.48, F(1,595)=6.36, p<.00$

Model $3: R=.20 ; \mathrm{R}^{2}=.04$, Adjusted $R^{2}=.04, S E=9.81, F(2,594)=12.44, p<.00$

Note. $\mathrm{N}=597 ; \mathrm{CI}=$ confidence interval; $\mathrm{PAP}=$ performance approach goals; $\mathrm{SL}=$ surface learning; Acad. $=$ Academic Achievement.

A regression model of mediation of surface learning strategy in the relationship between performance-approach goals and academic achievement is presented in Table 4.24. A series of multiple regression analyses were conducted to test whether surface learning strategy mediated the relationship between performance-approach goals and academic achievement. In the first step, performance-approach goals predicted academic achievement $(F(1,595)=20.46, p<.00)$ providing evidence of a significant relationship to be mediated. Performance-approach goals were found to be significantly related to academic achievement $(\beta=.18)$. There was a statistically significant relationship between performance-approach goals and surface learning strategy, $(F(1,595)=6.36, p<.01)$. It indicated that an increase in performance-approach goals corresponded to an increase in surface learning strategy. The relationship between surface learning strategy and academic achievement was statistically significant $(F(2,594)$ $=.12 .44, p<.01)$ when controlling for performance-approach goals. An increase in surface learning strategy was associated with an increase in academic performance.

The results showed that performance-approach goals were related to academic achievement when controlled for surface learning, confirming evidence of a partial mediation. 
Performance-approach goals were related to academic achievement; $\mathrm{t}=26.96, p<.01$. Coefficient $\mathrm{c}=.17$ was significant. Performance-approach goals were related to surface learning strategy; $\mathrm{t}=3.21, p<.01$.Coefficient $\mathrm{a}=.13$ was significant. The surface-learning strategy was related to academic achievement when controlled for performance-approach goals; $\mathrm{t}=2.08, p<.04$. Coefficient $\mathrm{b}=.08$ was significant. Performance-approach goals were related to academic achievement when controlled for surface-learning strategy; $\mathrm{t}=4.29, p<.01$. Coefficient $\mathrm{c}^{\prime}=.17$ was significant. Beta decreased from .18 to .17 showing partial mediation. The findings led to the conclusion that surface learning strategy partially and significantly mediated the relationship between performance-approach goals and academic achievement.

Finally, multiple regression analyses were conducted to test whether surface and deep learning strategies mediated the relationship between performance-avoidance goals and academic achievement. In step 1, the performance-avoidance goal was a significant predictor of academic achievement (path c).In step 2, when performance-avoidance goals were correlated with surface and deep learning strategies, there were no significant relationships. The performance-avoidance goal was therefore dropped from further mediation analysis.

\subsection{Discussions of the Results}

The study examined the extent to which learning strategies mediated the relationship between personal achievement goals and students' academic achievement. The current study found that deep learning strategy partially and significantly mediated the relationship between mastery goals and academic achievement. The findings suggest that mastery goals are likely to promote the use of high-quality learning strategies by students in activities that promote academic achievement. The current findings are in line with results reported by Mouratidis et al. (2018), which equally found that mastery-approach goals were positively related to challenge-seeking, which in turn, positively predicted academic achievement. The current results are also consistent with findings by Miškulin et al. (2017) which showed that deep learning mediated the relationship between mastery goals and academic achievement.

The current study found that surface learning strategy partially and significantly mediated the relationship between performance-approach goals and academic achievement. This is in line with achievement goal theory which states that performance-approach goals are associated with adoption of surface learning strategies to protect self-worth. The finding is also in line with Nasiri et al. (2017), results that reported there surface-learning strategies mediated the relationship between performance orientation and academic achievement. However, whereas the current study reported a positive correlation, Nasiri et al., found a negative association. The current results are also in line with Senko et al. (2013) whose findings revealed a link between achievement goals, learning strategies and exam performance, by showing that, students who adopted performance-approach goals scored high grades on the exams. The current study also reported similar findings as Senko et al. (2013) who had indicated that students who pursued mastery goals scored high marks. The current study found that deep learning strategy did not significantly mediate the relationship between performance-avoidance goals and academic achievement. The current findings showed that mastery goals significantly predicted deep learning. It, however, reported an insignificant correlation between performance-approach 
goals and deep learning strategy. Instead, performance-approach goals significantly predicted surface learning strategy. This was inconsistent with findings by Kadioglu et al. (2014) which reported that both mastery-approach and performance-approach goals significantly predicted deep learning strategies.

\section{Summary, Conclusion and Recommendations}

\subsection{Summary and Conclusion}

The study was to determine the mediating role of learning strategies in the relationship between achievement goals and academic achievement. Deep learning strategy significantly but partially mediated the relationship between mastery goals and academic achievement. Surface learning strategies mediated the relationship between performance-approach goals and academic achievement. The mediating role of learning strategy in the relationship between performance-avoidance goals and academic achievement was not statistically significant. The results suggest that mastery goals combined with deep learning strategy may improve academic achievement.

\subsection{Recommendations}

Based on the research findings, the following recommendations were made for further research and policy. The study highlights the need to advise teachers to create a learning environment that can embrace the two goals approach to serve students with either goal, thus, enabling them to learn deeply and perform well at the same time.

\subsubsection{Recommendations for Further Research}

Given that both mediating variables, deep and surface learning strategies, were validated in the present study, future research may further extend the trichotomous achievement goal framework by also considering the role of other mediators such as, self-efficacy, effort, strategic learning strategies, or self-concept, which have also been considered as important determinants of learning behaviour and outcome in other studies.

\section{References}

Anderman, E. M., Griesinger, T., \& Westerfield G. (1998). Motivation and cheating during early adolescence. Journal of Educational Psychology, 90(1), 84-93.

https://doi.org/10.1037//0022-0663.90.1.84

Anderman, E. M., \& Patrick, H. (2012). Achievement goal theory, conceptualization of ability, intelligence, and classroom climate, In. S.L.Christenson and A. L. Reschly (Eds.), Hand book of Research on Student Engagement. Springer Science + Business Media. https://doi.org/10.1007/978-1-4614-2018-7_8

Baron, R. M., \& Kenny, D. A. (1986). The moderator-mediator variable distinction in social psychological research: Conceptual, strategic, and statistical considerations. Journal of $\begin{array}{llll}\text { Personality and Social } & \text { Psychology, } & \text { 51, } & \text { 1173-1182. }\end{array}$ http://dx.doi.org/10.1037/0022-3514.51.6.1173 
Bücker, S., Nuraydin, S., Simonsmeier, B. A., Schneider, M., \& Luhmann, M. (2018). Subjective well-being and academic achievement: A meta-analysis. Journal of Research in Personality, 74(2018), 83-94. https://doi.org/10.1016/j.jrp.2018.02.007

Duzan, H., \& Shariff, N. S. (2016). Solution to the multicollinearity problem by adding some constant to the diagonal. Journal of Modern Applied Statistical Methods, 15(1), 752-773. https://doi.org/10.22237/jmasm/1462077360

Elliot, A. J. (1999). Approach and avoidance motivation and achievement goals. Educational Psychologist, 34(3), 169-189. https://doi.org/10.1207/s15326985ep3403_3

Grant, H., \& Dweck, C. S. (2003). Clarifying achievement goals and their impact. Journal of Personality and Social Psychology, 85, 541-553. https://doi.org/10.1037/0022-3514.85.3.541

Hornstra,L. Majoor,M. Peetsma,T.(2017). Achievement goal profiles and developments in effort and achievement in upper elementary school. British Journal of Educational Psychology, 87, 606-629. https://doi.org/10.1111/bjep.12167

Kadioglu, C. (2014). Relationship between learning strategies and goal orientations: A multilevel analysis. Eurasian Journal of Educational Research, 56, 1-22. https://doi.org/10.14689/ejer.2014.56.4

Kock, N., \& Lynn, G. (2012). Lateral collinearity and misleading results in variance-based SEM: An Illustration and recommendations. Journal of the Association for Information Systems, 13(7), 546-580. https://doi.org/10.17705/1jais.00302

Lewis, J., \& Linzer, D. (2005).Estimating regression models in which the dependent variable is based on estimates. Political analysis, 13(4), 345-364. https://doi.org/10.1093/pan/mpi026

McMillan, J. H. (2012). Educational Research: Fundamentals for the Consumer (6th ed.). Boston: Pearson.

Miškulin, N., \& Vrdoljak, G. (2017). Predicting academic achievement based on goal orientations and study approaches. Croatian Journal of Education, 19(3), 919-946. https://doi.org/10.15516/cje.v19i3.2178

Mouratidis, A., Michou, A., Demircioğlu, A. N., \& Sayil, M. (2018). Different goals, different pathways to success: Performance-approach goals as direct and mastery-approach goals as indirect predictors of grades in mathematics. Learning and Individual Differences, 61, 127-135. https://doi.org/10.1016/j.lindif.2017.11.017

Nasiri, E., Pour-Safar, A., Taheri, M., Sedighi Pashaky, A., \& Asadi Louyeh, A. (2017). Presenting the students' academic achievement causal model based on goal orientation. Journal of Advances in Medical Education \& Professionalism, 5(4), 195-202.

Pallant, J. (2007). SPSS survival manual: A step by step guide to data analysis using SPSS for Windows (3rd ed.). Maidenhead: Open Univ. Press.

Peetsma, T., \& Van der Veen, I. (2013). Avoidance-oriented students' development in motivation for maths self-regulated learning behaviour and achievement: A person-centred 


\section{Macrothink}

International Journal of Learning and Development

ISSN 2164-4063 2019, Vol. 9, No. 3

study in the lowest level of secondary education. Educational Psychology, 33, 828-848. https://doi.org/10.1080/01443410.2013.802885

Phan, H. P. (2013). The predictiveness of achievement goals: A $2 \times 2$ framework analysis from a social cognitive perspective. Europe's Journal of Psychology, 9(4), 697-716. https://doi.org/10.5964/ejop.v9i4.640

Salkind, N. J. (2010). Encyclopedia of research design Thousand Oaks. CA: SAGE Publications, Inc. https://doi.org/10.4135/9781412961288

Senko, C., Hama, H., \& Belmonte, K. (2013). Achievement goals, study strategies, and achievement: A test of the "learning agenda" framework. Learning and Individual Differences, 24, 1-10. https://doi.org/10.1016/j.lindif.2012.11.003 


\section{APPENDIX}

\section{Questionnaire for Students}

Part I: Achievement Goal Questionnaire

Read the following statements carefully and tick $(\sqrt{ })$ the answer that describes best what you think about your personal achievement goals.

$\mathrm{SD}=$ strongly disagree $\quad \mathrm{D}=$ disagree $\quad \mathrm{U}=$ undecided $\quad \mathrm{A}=$ agree $\quad \mathrm{SA}=$ strongly agree
1
2
3
4
5

Section I: Mastery Goals

\begin{tabular}{|c|c|c|c|c|c|c|}
\hline \multicolumn{2}{|c|}{ Statement } & \multirow[t]{2}{*}{$\mathrm{SD}$} & \multirow[t]{2}{*}{$\mathrm{D}$} & \multirow[t]{2}{*}{$\mathrm{U}$} & \multirow[t]{2}{*}{ A } & \multirow[t]{2}{*}{ SA } \\
\hline 1 & $\begin{array}{l}\text { Understanding the subject content, to me, is more } \\
\text { important than the grade I get. }\end{array}$ & & & & & \\
\hline 2 & $\begin{array}{l}\text { I like school work that I learn from even if I make } \\
\text { mistakes. }\end{array}$ & & & & & \\
\hline 3 & $\begin{array}{l}\text { My goal in this school is to do my best, even if } \\
\text { others are doing better. }\end{array}$ & & & & & \\
\hline 4 & $\begin{array}{l}\text { It's crucial to me that I thoroughly understand what } \\
\text { I learn in class. }\end{array}$ & & & & & \\
\hline 5 & $\begin{array}{l}\text { The main reason I do my school work is to learn as } \\
\text { much as I can. }\end{array}$ & & & & & \\
\hline 6 & $\begin{array}{l}\text { I prefer work that really makes me think even if it's } \\
\text { difficult to learn. }\end{array}$ & & & & & \\
\hline 7 & $\begin{array}{l}\text { I feel most successful in class when I learn } \\
\text { something new that I didn't know before. }\end{array}$ & & & & & \\
\hline 8 & $\begin{array}{l}\text { I'm more concerned with doing my best than doing } \\
\text { better than others. }\end{array}$ & & & & & \\
\hline
\end{tabular}


Section II: Performance-Approach Goals

\begin{tabular}{|c|c|c|c|c|c|c|}
\hline \multicolumn{2}{|c|}{ Statement } & SD & D & U & A & SA \\
\hline 1 & $\begin{array}{l}\text { It feels good when I'm the only student in class who } \\
\text { could answer questions asked by the teacher. }\end{array}$ & & & & & \\
\hline 2 & $\begin{array}{l}\text { I like to display to my teachers that I'm brighter than } \\
\text { my fellow students. }\end{array}$ & & & & & \\
\hline 3 & $\begin{array}{l}\text { I try to do well in this school so that teachers will } \\
\text { recognize that I'm brighter than other students in the } \\
\text { class. }\end{array}$ & & & & & \\
\hline 4 & $\begin{array}{l}\text { I'm more interested in doing better than the other } \\
\text { students in my class, than doing my best. }\end{array}$ & & & & & \\
\hline 5 & $\begin{array}{l}\text { I want to do well in exams to show my parents that } \\
\text { I'm brighter compared to other students in my class. }\end{array}$ & & & & & \\
\hline 6 & $\begin{array}{l}\text { It's important to me that I do well compared to others } \\
\text { in class }\end{array}$ & & & & & \\
\hline 7 & $\begin{array}{l}\text { My main goal in this school is to score the best grade } \\
\text { in the class. }\end{array}$ & & & & & \\
\hline
\end{tabular}




\section{Macrothink \\ International Journal of Learning and Development \\ ISSN 2164-4063 2019, Vol. 9, No. 3}

Section III: Performance-Avoidance Goals

\begin{tabular}{|c|c|c|c|c|c|c|}
\hline \multicolumn{2}{|c|}{ Statement } & $\mathrm{SD}$ & $\mathrm{D}$ & $\mathrm{U}$ & A & SA \\
\hline 1 & $\begin{array}{l}\text { It's crucial to me that I don't appear unintelligent } \\
\text { in class. }\end{array}$ & & & & & \\
\hline 2 & $\begin{array}{l}\text { Keeping others from thinking I'm not intelligent in } \\
\text { class is one of my goals. }\end{array}$ & & & & & \\
\hline 3 & $\begin{array}{l}\text { It's important to me that teachers don't get to know } \\
\text { that I'm not as intelligent as the others in the class. }\end{array}$ & & & & & \\
\hline 4 & $\begin{array}{l}\text { One goal for me in school is to avoid looking like I } \\
\text { have difficulty doing my class work. }\end{array}$ & & & & & \\
\hline 5 & $\begin{array}{l}\text { I fear that if I ask my teachers or classmates for } \\
\text { assistance in doing class work they may think I'm } \\
\text { not intelligent. }\end{array}$ & & & & & \\
\hline 6 & $\begin{array}{l}\text { When my classmates ask how I did on a test or } \\
\text { assignment I usually lie by saying I did better than } \\
\text { I actually did. }\end{array}$ & & & & & \\
\hline 7 & $\begin{array}{l}\text { When tests results or assignments are returned I do } \\
\text { not want others to know the marks I got. }\end{array}$ & & & & & \\
\hline
\end{tabular}


Part II : Students Learning Strategies

Read the following statements carefully and tick $(\sqrt{ })$ the answer that best describes how you usually respond when preparing for your academic performance.

Section I: Surface Learning Strategy Scale

\begin{tabular}{|c|c|c|c|c|c|c|}
\hline \multicolumn{2}{|c|}{ Statement } & SD & D & $\mathrm{U}$ & A & SA \\
\hline 1 & $\begin{array}{l}\text { When I prepare for the exam, I ensure that I have } \\
\text { memorized as many facts as possible. }\end{array}$ & & & & & \\
\hline 2 & $\begin{array}{l}\text { When I prepare for exams, I read the text books } \\
\text { and lesson notes and search for the main ideas to } \\
\text { memorize. }\end{array}$ & & & & & \\
\hline 3 & $\begin{array}{l}\text { When I prepare for exams, I read text books and } \\
\text { lesson notes repeatedly so as to remember the } \\
\text { facts. }\end{array}$ & & & & & \\
\hline 4 & $\begin{array}{l}\text { When I study I memorize key terms in each } \\
\text { chapter of the text book. }\end{array}$ & & & & & \\
\hline 5 & $\begin{array}{l}\text { I try to remember everything that I think might be } \\
\text { tested in the exam. }\end{array}$ & & & & & \\
\hline
\end{tabular}


Section II: Deep Learning Strategy Scale

\begin{tabular}{|c|c|c|c|c|c|c|}
\hline \multicolumn{2}{|c|}{ Statement } & \multirow[t]{2}{*}{$\mathrm{SD}$} & \multirow[t]{2}{*}{ D } & \multirow[t]{2}{*}{$\mathrm{U}$} & \multirow[t]{2}{*}{ A } & \multirow[t]{2}{*}{ SA } \\
\hline 1 & $\begin{array}{l}\text { When I study I do enough work on a topic so that I } \\
\text { can form my own conclusion before I can feel } \\
\text { satisfied. }\end{array}$ & & & & & \\
\hline 2 & $\begin{array}{l}\text { When a point is presented in class or in a textbook, } \\
\text { I try to check if there is supporting evidence. }\end{array}$ & & & & & \\
\hline 3 & $\begin{array}{l}\text { I treat the information I'm taught as a starting } \\
\text { point and then try to add my own ideas about it. }\end{array}$ & & & & & \\
\hline 4 & $\begin{array}{l}\text { When I read or hear a point I also think of possible } \\
\text { alternatives. }\end{array}$ & & & & & \\
\hline 5 & $\begin{array}{l}\text { I never question the information presented by the } \\
\text { teacher or in the textbook. }\end{array}$ & & & & & \\
\hline 6 & $\begin{array}{l}\text { I think through topics and decide what to learn } \\
\text { from them instead of just reading them over. }\end{array}$ & & & & & \\
\hline
\end{tabular}

THANK YOU FOR YOUR PARTICIPATION

\section{Copyright Disclaimer}

Copyright for this article is retained by the author(s), with first publication rights granted to the journal.

This is an open-access article distributed under the terms and conditions of the Creative Commons Attribution license (http://creativecommons.org/licenses/by/4.0/). 